\title{
RESEÑ̃́S
}

\section{Corporalidades in-mundas Comentario al libro Extraña Permanencia de Eugenia Brito ${ }^{1}$}

Eugenia Brito. Extraña permanencia. Editorial Cuarto Propio, Santiago, 2004.

\section{Cecilia Sánchez ${ }^{2}$}

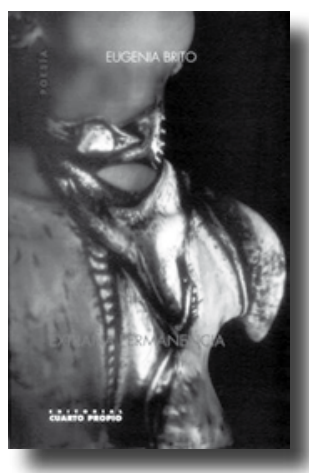

Los estilos de (la) poeta

Es extraño el escrito de Eugenia Brito que aquí comento, el que ella -acaso anticipándose al ingreso de sus lectores- rotuló Extraña permanencia. Al leer este libro, experimento una sensación de desconcierto de la que me agarro para intentar nombrar lo que no parece formar parte de una legalidad reconocible a nivel de la composición. Cuando se identifica un estilo, lo que se vuelve apreciable es la coincidencia con un ordenamiento conocido o familiar. Me atrevo a sostener que el escrito de Eugenia Brito parece ajeno a un estilo reconocible por el criterio del gusto. Me gustaría enumerar algunos estilos, todavía dominantes en la poesía, para apreciar cuán lejos se encuentra este escrito de algunos de ellos.

Desde la partida, no corresponde leer a Eugenia Brito desde una poética del entusiasmo, en donde la escritura se ejerce a partir de un don que viene de los dioses o de las fuerzas femeninas de las musas, figuras de la manía -diría Platón- que encarnan la alteridad con la que se conecta el o la poeta. En caso de prescindir de las musas o de los dioses, los resabios de un cierto romanticismo, presente 
todavía en las formas de apreciación de lo que se entiende por literatura, mueve a muchos lectores a buscar lo poético en el vuelo espontáneo de la mente de un genio iluminado. La escritura de Brito tampoco responde a aquella excepcionalidad ni a la operación creacionista en que el poeta es un "pequeño Dios" que hace nacer palabras desde la nada. Ninguno de estos estilos reconozco en el libro de Eugenia Brito.

Cabe recordar que Chile gusta de hacerse reconocer en ciertas ocasiones como un "país de poetas." Si bien para Patricio Marchant resulta imposible llegar a ser filósofo(a)s en Chile, sí reconoce la posibilidad de que algún joven se plantee un destino de poeta y lo cumpla, en parte debido -como él dice- a la seriedad de las exigencias de la poesía en Chile. ${ }^{3}$ En virtud de esta identidad, se le ha otorgado a dicha palabra un lugar visible y ella es celebrada mientras se haga oír y leer en la dimensión logo-fundante de una comunidad que coincide consigo misma. Aunque, debo admitir, han terminado por aceptarse en la escritura poética -no sin resistencia- ciertas fisuras irónicas que, como las de Nicanor
Parra, rompen en cierto modo la mansedumbre del lenguaje pleno, brillante y espontáneo. En todo caso, ninguna de las modalidades de estilo recién mencionadas, incluyendo la irónica, se espera que formen parte del ejercicio de escritura delas mujeres. El topos intimista que la tradición le concede a las mujeres, las insta a que su subjetividad tenga como único anhelo de sus apetencias el amor, pero en modo alguno se espera que la palabra poética invoque el amor erótico ni aquél en que se encuentre en juego el poder. Sólo quedan disponibles el romántico-trascendental, el místico o el doméstico, especialmente el amor materno. Bajo el talante de esta candorosa forma de amar fueron aplaudidos los versos de Gabriela Mistral. La crítica destacó la inmediatez de sus escritos, pero ignoró el lado resentido, amargo y moribundo que atraviesa a la textualidad de esta maestra rural que se autocalificó de "pobre mujer herida."

El texto de Eugenia me parece responder a otra lógica que, hasta donde la he leído, ya está presente en Dónde vas (1998), su trabajo anterior. Su palabra carece de musa, de dioses, de entusiasmo y espontaneidad, pero no de 
alteridad. Por el contrario, merodea en las proximidades de lo que yo llamaría escritura sagrada, pues se inmiscuye con el placer y el dolor que, como extremos del cuerpo, se encuentran regulados socialmente por interdictos. Así, su escritura entra en disputa con la ley del discurso para privilegiar un decir residual, dado a leer en la letra como marca material en permanente rearticulación, según explicitaré en el momento en que ingrese en los detalles de su libro.

Ante todo, me interesa precisar que el momento corporal del discurso no ha cesado de pasarse por alto, especialmente por el escritor letrado, quien autoriza su ingreso al espacio de la hoja de papel desde un saber escolar (hoy rotulado de alta cultura). Para ser tal, el discurso letrado internaliza las jerarquías inscritas en la dicotomía cuerpo/alma. La pasividad del cuerpo material se redime de su prosaico destino de ser materia desechable y accidental si se subordina a una forma sublimada que al contenerlo lo eterniza y lo pone en movimiento. El estilo ha sido el corsé disciplinador que institucionaliza y devuelve como cultura la experiencia de la marca en fuga que es la escritura.
En el caso del libro de Eugenia Brito, el gesto que me llama la atención es su forma escénica de combinar los hilos de una palabra narrativa con los de la poética, ya que cuenta una historia cuya temporalidad está marcada por deslizamientos y borrones. Se trata de restos de voces que jamás podrían haberse presentado de modo pleno, pues carecen de identidad y de registro. Como se verá, los dispositivos de este trabajo son residuos enmarañados que se repiten y circulan de modo ciego. Podría decirse que son narraciones que circulan a su propio ritmo y bajo los cuerpos enigmáticos de cicatrices y marcas que son superficies de una memoria que ya no recuerda algo con sentido, pero que insisten en permanecer como huellas o como ficciones que vienen de la desesperanza.

\section{La Permanencia in- munda del residuo}

En Extraña permanencia, la escritura se pliega a la temporalidad de las hojas del calendario en la que se encuentran marcadas dos fechas: $1975 \mathrm{y}$ 1995.

El espaciamiento de veinte 
años que separa las dos fechas mencionadas tiene la economía de una escena. El mismo texto se hace la pregunta: "¿cuándo se entra en escena?" Si bien la palabra "escena" subsume la totalidad del escrito, a modo de respuesta selecciono el siguiente párrafo:

Se entra cuando se desea olvidar un secreto o bien cuando se escucha un nombre en una clave perdida para la memoria y esa clave atisba el sector borrado que es el que contiene todo el tejido del goce y del sufrimiento vivido (14).

Como dije anteriormente, la escritura de este libro se abre al tiempo sagrado de corporalidades agonizantes que experimentan el nomadismo y la desafiliación. El tiempo invocado es el de la dictadura, situación que los obliga a transitar en condición de sombras por callejones, subterráneos y acueductos. La letra a la que se acude para escribir el tránsito de estos cuerpos se compone de borraduras y exclusiones, cuyos residuos corresponden a la pulsación de una extraña permanencia. La letra se toma aquí, como escribió Lacan, para demarcar la relación en- tre inconsciente y escritura, "al pie de la letra." Es decir, a la escritura así planteada no cabe leerla en clave de un discurso ordenado, sino que es atravesada por las figuras trópicas del significante que se resiste a convertirse en significado.

El texto insinúa un recorrido no lineal entre dos escenarios relacionados con las fechas que marcan la letra de este escrito. Los actores que forman parte de las voces y los gestos de las letras apenas retienen un plan para la escena, pero su actitud no es una falla ni un descuido pues respetan la ley del escenario en el que ingresan. Cabe precisar que el escenario acerca del que se escribe no es un lugar del mundo. Por el contrario, éste es un lugar que ha sido despojado del poder discursivo que forma parte del habla de la polis, reconvirtiéndose en el lugar que permite la circulación de un discurso in-mundo (sin orden ni lugar) que permite el flujo de un diálogo descortés y sin vigilancia. En este escenario, los actores entregan la piel a este tiempo ritual, "soportan mucho para ganar una ficción" (12). Especialmente Adela, en quien se concen- 
tran los secretos de un cuerpo ciego y victimado, excesivo y elíptico. Ella se articula en la errancia, "inclinada a la noche y al irreprimible sello del deseo" (11). Jacinta, en cambio, es su reverso pues se instituye por "la ley burguesa del intercambio" (125). Ambas son el reverso y el anverso de un mismo sujeto escindido, de cuya tensión quisiera usufructuar Mauricio: el libretista. El deseo de Mauricio es presenciar la lucha erótica de ambos cuerpos: "como hombre contra hombre" (126).

A su vez, el texto es sacudido por la irrupción del paso de un avión hacia el norte. En ese momento se demarcan las coordenadas que abren el texto de Eugenia Brito a la temporalidad de veinte años después. El avión es el lugar escénico de tensión entre el cuerpo rubio y la feminización del latino. El teatro lucha por configurar manuscritos que son ecos guturales y reflejos de la realidad espectral de un cuerpo único, suerte de horda primitiva sobre la que delira una historia que traspasa sus vísceras. La historia también es una maquinaria inútil que muestra lo femenino del cuerpo del hombre y de la mujer latina en el punto de tensión entre materiales duros que lo modelan, pero que de igual modo permiten apreciar la manera en que este poder se ejerce en la única zona libre que queda: los pelos axilares.

Con un tono de lamento $\mathrm{u}$ oración, podría decirse que Brito escribe para invocar un texto borrado, compuesto por "una violenta gramática de pérdidas y mutaciones" (102). Sin telos que la articule, esta segunda escritura parece encarnar la figura de la cartonera que se da a la tarea de entretejer residuos cuya trama es modelada por los signos binarios de la "joya" y la "basura."

El sombrío altillo de los cuerpos nómades muta y termina convertido en un espacio de oficina, cuya disponibilidad se ofrece al cruce empresarial de mercados europeos y americanos. El cuerpo subterráneo es ahora un cuerpo maquinal. El poder que lo traspasa ya no es el militar, se imponen ahora los destellos de una pantalla iluminada. Los suburbios se transforman en erratas que consisten en "piedras y lodo, perros y niños que chillan hambrientos, ropas que se tienden aleteando como buitres que esperan su carroña[...]" (90).

Debo decir, para terminar, 
que mi comentario optó por perseguir el pulso de la poética en juego en el libro y seguir de modo accesorio su secuencia narrativa. Desde esta perspectiva el relato de Eugenia Brito es una contraescena, movilizada por un deseo de máscaras. Bajo tales términos, se inscribe en una poética de la memoria que se hace cargo de lo que permanece sin sentido. El texto es, así, enteramente dispendioso, pues al querer recuperar un fantasma inasible mediante guiones, coros, manuscritos, nombres y roles, se vuelve balbuceo que carece de una restitución luminosa.

\section{Notas}

1 Texto leído en la presentación del libro Extraña permanencia (Editorial Cuarto Propio, 2004), realizada en enero de 2005 en la sala Juan Egenau de la Escuela de Bellas Artes de la Universidad de Chile.

2 Licenciada en Filosofía en la Universidad de Chile (1989). Realizó estudios de postgrado en la Université Paris VIII (1991). Es autora de Una disciplina de la distancia. Institucionalización universitaria de los estudios filosóficos en Chile (Cerc-Cesoc, 1992) y Escenas del cuerpo escindido. Ensayos cruzados de filosofía, literatura y arte (Editorial Cuarto Propio, 2005). Ha publicado numerosos artículo en revistas libros nacionales e internacionales acerca de la institucionalidad de la filosofía, del pensamiento en Chile y en Latinoaméri$\mathrm{ca}$, de problemas de género $\mathrm{y}$ de filosofía contemporánea. Se desempeña como profesora de filosofía en las Universidades ARCIS, de Chile, Academia de Humanismo Cristiano, Diego Portales y de Talca.

3 Patricio Marchant se refiere a la situación relevante del poeta en Chile en desmedro de la del filósofo, en su libro Sobre árboles y madres. Santiago de Chile: Ediciones Gato Mur, 85. 